\title{
TGF- $\beta 1$ induces the formation of vascular-like structures in embryoid bodies derived from human embryonic stem cells
}

\author{
YAN WANG $^{1}$, DE-JIAN QIAN ${ }^{1}$, WEN-YU ZHONG ${ }^{2}$, JUN-HONG LU $^{3}$, \\ XIANG-KAI GUO ${ }^{1}$, YI-LIN CAO ${ }^{3}$ and JU LIU ${ }^{1,4}$
}

\author{
${ }^{1}$ Department of Plastic Surgery, Provincial Qianfoshan Hospital Affiliated to Shandong University, Jinan, \\ Shandong 250014; ${ }^{2}$ Department of Gynecology and Obstetrics, Jinan Central Hospital, Jinan, Shandong 250013; \\ ${ }^{3}$ Department of Plastic and Reconstructive Surgery, Shanghai Ninth People's Hospital, Shanghai 200011; \\ ${ }^{4}$ Medical Research Center, Shandong Provincial Qianfoshan Hospital, Jinan, Shandong 250014, P.R. China
}

Received January 4, 2013; Accepted May 14, 2014

DOI: $10.3892 / \mathrm{etm} .2014 .1721$

\begin{abstract}
Human embryonic stem cells (ESCs) can differentiate into endothelial cells in response to stimuli from extracellular cytokines. Transforming growth factor (TGF)- $\beta 1$ signaling is involved in stem cell renewal and vascular development. Previously, human ESCs were isolated from inner cell mass and a stable ESC line was developed. In the present study, the effects of extracellular TGF- $\beta 1$ were investigated on human ESC-derived embryoid bodies (EB) in suspension. The structures of the EBs were analyzed with light and electron microscopy, while the cellular composition of the EBs was examined via the expression levels of specific markers. Vascular-like tubular structures and cardiomyocyte-like beating cells were observed in the EBs at day 3 and 8, respectively. The frequencies of vascular-like structures and beating cells in the TGF- $\beta 1$ treated group were significantly higher compared with the control group (84.31 vs. $12.77 \%$; $\mathrm{P}<0.001$; 37.25 vs. $8.51 \%$; $\mathrm{P}<0.001$, respectively). Electron microscopy revealed the presence of lumens and gap junctions in the sections of the tubular structures. Semiquantitative polymerase chain reaction revealed elevated expression levels of CD31 and fetal liver kinase-1 in EBs cultured with TGF- $\beta 1$. In addition, extensive staining of von Willebrand factor was observed in the vascular-like structures of TGF- $\beta 1$-treated EBs. Therefore, the results of the present study may aid the
\end{abstract}

Correspondence to: Dr Ju Liu, Department of Plastic Surgery and Medical Research Center, Province Qianfoshan Hospital Affiliated to Shandong University, 16766 Jing Shi Road, Jinan, Shandong 250014, P.R. China

E-mail: jliu0228@gmail.com

Dr Yi-lin Cao, Department of Plastic and Reconstructive Surgery, Shanghai Ninth People's Hospital, 639 Manufacturing Bureau Road, Shanghai 200011, P.R. China

E-mail: yilincao@yahoo.com

Key words: human embryonic stem cell, transforming growth factor- $\beta$, embryoid body, endothelial cell understanding of the underlying mechanisms of human ESC differentiation and improve the methods of propagating specific cell types for the clinical therapy of cardiovascular diseases.

\section{Introduction}

Human embryonic stem cells (ESCs) are self-renewing pluripotent cells that can differentiate into a wide variety of cell types under specific in vitro culture conditions (1). These cells offer a promising source to treat a number of human diseases by providing an unlimited supply of different cell types, including endothelial cells (ECs) for therapeutic neovascularization and cardiomyocytes for repairing heart failure damage (2-5). Although human ESC-derived ECs and cardiomyocytes have been reported, the underlying mechanisms of differentiation and maintenance of cell fate remain unclear. Understanding the molecular biology of human ESCs may help to identify the factors promoting a cardiovascular fate and improve ESC culture conditions, which may lead to novel therapeutic methods for the treatment of cardiovascular diseases.

Several cytokines have been shown to facilitate the differentiation of ESCs into ECs. One such cytokine is transforming growth factor (TGF)- $\beta 1$, a highly conserved protein produced by a variety of cells (6). TGF- $\beta 1$ is a member of the TGF- $\beta$ superfamily, which plays a key role in the regulation of human ESCs $(6,7)$. TGF- $\beta 1$ activates its receptors through ligand binding, which is followed by oligomerization of serine/threonine receptor kinases and the phosphorylation of the cytoplasmic signaling SMAD proteins that regulate the transcription of targeted genes (8). Targeted gene deletions of TGF- $\beta 1$ and its receptors, TGF- $\beta$ R $1 / 2$, result in abnormal vascular development of mouse embryos, particularly of the yolk sac, leading to embryonic lethality (9-11). A number of studies have commonly indicated a requirement for TGF- $\beta 1$ to support self-renewing cultures of human ESCs. For example, the inhibition of TGF receptors with a compound resulted in rapid differentiation of human ESCs (12-14).

When allowed to differentiate in suspension, ESCs develop cystic embryoid bodies (EBs) that have specific 
Table I. Oligonucleotide primers used for semiquantitative PCR analysis.

Annealing

\begin{tabular}{|c|c|c|c|c|}
\hline Gene & Primer sequence & temperature, ${ }^{\circ} \mathrm{C}$ & Cycles, $\mathrm{n}$ & Size, $b^{a}$ \\
\hline FLK1 & $\begin{array}{l}\text { 5'-CCTACCCCACACATTACATGG-3' } \\
\text { 5'-TTTTCCTGGGCACCTTCTATT-3' }\end{array}$ & 58 & 30 & 200 \\
\hline CD31 & $\begin{array}{l}\text { 5'-AGGAAAGCCAAGGCCAGG-3' } \\
\text { 5'-CCTTGCTGTCTAAGTCCT-3' }\end{array}$ & 58 & 30 & 354 \\
\hline$\beta$-actin & $\begin{array}{l}\text { 5'-AGGTGACAGCATTGCTTCTG-3' } \\
\text { 5'-GCTGCCTCAACACCTCAAC-3' }\end{array}$ & 58 & 30 & 188 \\
\hline
\end{tabular}

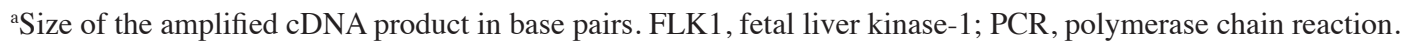

features of early post-implantation embryos. Notably, EB formation from mouse ESCs has already been extensively utilized and validated as an in vitro model of early mouse development (15-18). Mouse ESCs transfected with a $1.7 \mathrm{~kb}$ cDNA of porcine TGF- $\beta 1$ were shown to be able to differentiate into EBs with outspread tubular structures and increased endothelial marker expression (19). However, human and mouse ESCs have disparate responses to extracellular stimuli (7). In a study of human ESCs collected from the yolk sac, Poon et al found that TGF- $\beta 1$ inhibited the expression of endodermal and hematopoietic markers, which is in contrast to the observations with mouse ESCs (7). To date, the roles of TGF- $\beta 1$ in human ESCs derived from inner cell mass (ICM) remain unclear.

In previous research, human ESCs were isolated from the ICM of human blastocysts and were shown to have a normal karyotype, express specific pluripotent markers and propagate for extended periods of time (20). In the present study, these human ESCs were cultured, differentiated into EBs in suspension culture and transferred into medium containing TGF- $\beta 1$. The structures of the EBs were examined by light and electron microscopy, while the cellular composition of these structures was analyzed via the expression levels of several endothelial-specific markers.

\section{Materials and methods}

Cell culture. A human ESC line was previously established (21), with approval from the Internal Review Board on Human Subjects Research and Ethics Committees at Shanghai Ninth People's Hospital (Shanghai, China). Briefly, human ESCs were isolated from day 6 blastocysts and transferred onto a feeder layer of mitomycin-C- (Sigma-Aldrich, St. Louis, MO, USA) inactivated mouse embryonic fibroblasts (MEFs) in human ESC culture medium. The medium consisted of Dulbecco's Modified Eagle's medium (DMEM; Invitrogen Life Technologies, Carlsbad, CA, USA) supplemented with $20 \%$ KnockOut Serum Replacement (Invitrogen Life Technologies), $1 \%$ non-essential amino acids, $1 \mathrm{mM}$ L-glutamine, $0.1 \mathrm{mM} \beta$-mercaptoethanol and $4 \mathrm{ng} / \mathrm{ml}$ basic fibroblast growth factor (bFGF; R\&D Systems, Minneapolis, MN. USA). Cells were incubated at $37^{\circ} \mathrm{C}$ with $5 \% \mathrm{CO}_{2}$, and colonies were passed every 5-7 days using $1 \mathrm{mg} / \mathrm{ml} \mathrm{IV} \mathrm{colla-}$ genase.
Induction and formation of EBs. To induce EB formation, human ESC colonies were dissociated into small cell mass mechanically and grown in dishes covered with $1 \%$ agar in ESC culture medium containing $1 \times 10^{9} \mathrm{~mol} / 1$ retinoic acid (R2625; Sigma-Aldrich). Following culturing for 3-5 days, the cells aggregated and formed EBs. The EBs were then transferred into dishes covered with $0.1 \%$ gelatin and cultured in serum-free DMEM containing $3 \mathrm{ng} / \mathrm{ml}$ TGF- $\beta 1$ (240-B-010; R\&D Systems) or as controls with serum-free DMEM only. The culture medium was changed every $24 \mathrm{~h}$, and the morphological changes of the EBs were examined daily under a phase-contrast microscope. The images of beating cells of the EBs were stored on a videotape using a Nikon CCD camera (Nikon Corporation, Tokyo, Japan).

Semiquantitative polymerase chain reaction $(P C R)$ analysis. Total RNA isolation from the EBs was performed using TRIzol reagent (Invitrogen Life Technologies), according to the manufacturer's instructions. An aliquot of $2 \mu \mathrm{g}$ total RNA from each sample was used for the synthesis of cDNA using a High-Capacity cDNA Reverse Transcription kit (Applied Biosystems, Inc., Foster City, CA, USA). The first-strand cDNA (equivalent of $40 \mathrm{ng}$ reverse-transcribed RNA) was amplified in a final volume of $20 \mu \mathrm{l}$ with 1 unit TaqDNA polymerase (Invitrogen Life Technologies) and 10-pmol samples of each primer. The oligonucleotide primers are listed on Table I. The thermal-cycle program was as follows: $95^{\circ} \mathrm{C}$ for $5 \mathrm{~min}$ (one cycle); $94^{\circ} \mathrm{C}$ for $1 \mathrm{~min}, 58^{\circ} \mathrm{C}$ for $1 \mathrm{~min}$ and $72^{\circ} \mathrm{C}$ for $1 \mathrm{~min}$ (30 cycles); and $72^{\circ} \mathrm{C}$ for $5 \mathrm{~min}$ (one cycle). To ensure the accuracy of the quantitative results, the number of PCR cycles for each set of primers was validated in the linear range of amplification, and all cDNA samples were adjusted to yield equal amplifications of $\beta$-actin, which was used as the internal control. The PCR products were visualized by ethidium bromide staining following $1.2 \%$ agarose gel electrophoresis.

Immunofluorescence staining. EBs were fixed in 4\% paraformaldehyde for $10 \mathrm{~min}$, washed with phosphate-buffered saline (PBS) containing $0.25 \%$ Triton and incubated with rabbit anti-von Willebrand factor (vWF) antibodies (Dako, Ely, UK) at a working concentration of $1: 100$ for $1 \mathrm{~h}$ at $37^{\circ} \mathrm{C}$. Following washing with PBS, the EBs were incubated with goat anti-rabbit IgG (H\&L) secondary antibodies conjugated with fluorescein (Abnova Corporation, Taipei City, Taiwan) at a 
Table II. Number of EBs with vascular-like structures in the control and TGF- $\beta 1$-treated groups.

\begin{tabular}{lcccc}
\hline & \multicolumn{2}{c}{ Control } & \multicolumn{2}{c}{ TGF- $\beta 1$} \\
\cline { 2 - 5 } Group & EBs formed, $\mathrm{n}$ & EBs with VS, $\mathrm{n}(\%)$ & EBs formed, $\mathrm{n}$ & EBs with VS, $\mathrm{n}(\%)$ \\
\hline 1 & 15 & $2(13.33)$ & 18 & $15(83.33)$ \\
2 & 16 & $3(18.75)$ & 20 & $13(100)$ \\
3 & 16 & $1(6.25)$ & 51 & $15(75)$ \\
Total & 47 & $6(12.77)$ & $(84.31)$ \\
\hline
\end{tabular}

VS, vascular-like structures; EB, embryoid body; TGF, transforming growth factor. Groups 1-3 are repeats of the same experiment.

A

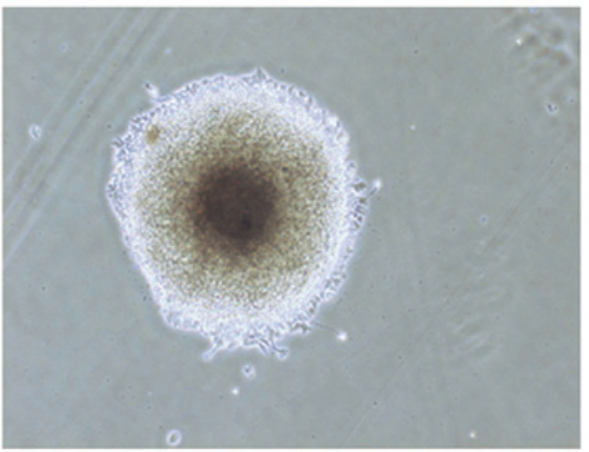

C



B

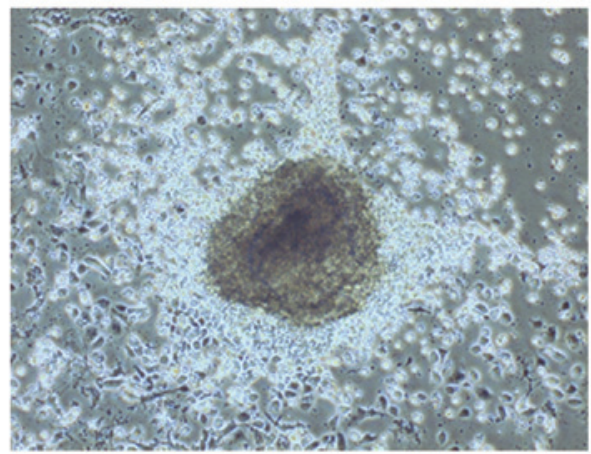

D

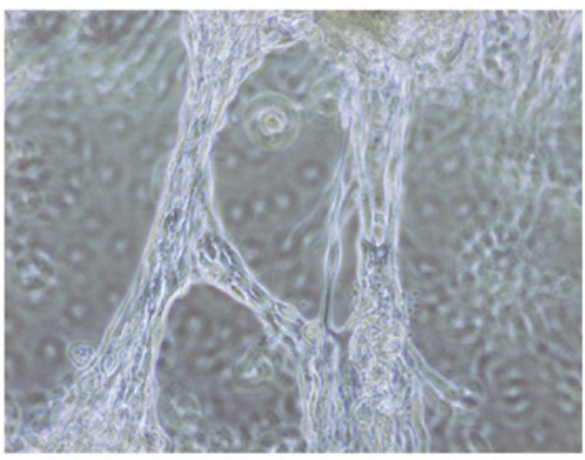

Figure 1. Morphology of human ESC-derived EBs (unstained images). (A) EBs in the control group exhibited a smooth margin; (B) EBs treated with TGF- $\beta 1$ demonstrated vascular-like structures with epithelial-like and round cells (magnification, x20), and (C) tube-like structures connected to the EBs (magnification, x40); (D) tube-like structures were observed at a higher magnification (magnification, x100). TGF, transforming growth factor; EBs, embryoid bodies; ESC, embryonic stem cell.

working concentration of 1:50 for $45 \mathrm{~min}$ at $37^{\circ} \mathrm{C}$. The samples were then mounted using glycerol and photographed with a fluorescent microscope. The negative control was prepared using the same protocol without primary antibody incubation.

Electron microscopy. Observations with a scanning electron microscope (SEM) were firstly conducted. The EBs were fixed with $2 \%$ glutaric dialdehyde, rehydrated in PBS, fixed again with osmic acid and washed in PBS. Next, the EBs were dehydrated by gradient alcohol with amyl acetate, dried with a Critical Point Dryer, sputter-coated by an ionic sprayer meter and observed with a SEM (S450; Hitachi, Ltd., Tokyo, Japan). Observations were also performed with a transmission electron microscope (TEM). The EBs were fixed with $2 \%$ glutaric dialdehyde for $1 \mathrm{~h}$ and osmic acid for $1 \mathrm{~h}$, dehydrated by gradient alcohol and incubated with 1:1 acetone embedding liquid in infiltration. The EBs were embedded with EPON and cut into ultra-thin sections, which were then observed with a TEM (JEM-1200EX; Jeol Ltd., Tokyo, Japan).

\section{Results}

Formation of EBs with tubular structures from human ESCs stimulated by TGF- $\beta 1$. Colonies of human ESCs were dissociated into small cell mass and grown on $1 \%$ agar. Following culturing in media containing retinoic acid for 4 days, the cell mass formed EBs, which adhered to the dishes and became semispheres. The EBs were then cultured in serum-free DMEM containing $3 \mathrm{ng} / \mathrm{ml}$ TGF- $\beta 1$, and epithelial-like and round cells appeared around the EBs after 1 day. On day 3, tube-like structures deriving from the round cells were observed, while the cells gradually transformed from round to flat shapes (Fig. 1A). Tube-like structures radiated from EBs to the outside (Fig. 1B). These tubular structures connected, 
Table III. Number of EBs with beating cells in the control and TGF- $\beta 1$-treated groups.

\begin{tabular}{lcccc}
\hline & \multicolumn{2}{c}{ Control } & & TGF- $\beta 1$ \\
\cline { 2 - 5 } Group & EBs formed, $\mathrm{n}$ & EBs with & EBs with \\
\cline { 3 - 5 } & 15 & $2(13.33)$ & 18 & $6(33.33)$ \\
2 & 16 & $1(6.25)$ & 13 & $4(30.77)$ \\
3 & 16 & $1(6.25)$ & 20 & $9(45)$ \\
Total & 47 & $4(8.51)$ & 51 & $19(37.25)$ \\
\hline
\end{tabular}

EB, embryoid body; TGF, transforming growth factor.

A

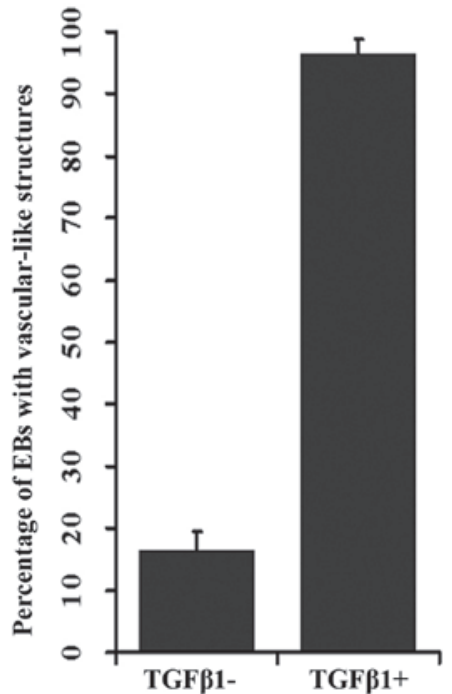

B



Figure 2. TGF- $\beta 1$ induced vascular and cardiac-like structures in human ESC-derived EBs. EBs were developed in suspension with and without TGF- $\beta 1$. Percentage of EBs with (A) vascular-like structures $(\mathrm{n}=3$; $\mathrm{P}<0.001)$ and $(\mathrm{B})$ beating cells $(\mathrm{n}=3$; $\mathrm{P}<0.001)$. TGF, transforming growth factor; EBs, embryoid bodies; ESC, embryonic stem cells.

extended and joined with each other to form a network (Fig. 1C and D). The frequencies of these structures in the control and TGF- $\beta 1$ treated groups were 12.77 and $84.31 \%$, respectively ( $\mathrm{P}<0.001$; Fig. 2A; Table II). At day 8, cardiomyocyte-like beating cells were observed in the EBs that had been treated with TGF- $\beta 1$. In addition, at day 10 , beating cells were observed in $37.25 \%$ of the EBs treated with TGF- $\beta 1$, while only in $8.51 \%$ of the EBs in the control $(\mathrm{P}<0.001$; Fig. $2 \mathrm{~B}$, Table III).

Characterization of the vascular-like structures by electron microscopy. SEM images exhibited a three-dimensional morphology of the EBs. The tubular structures were composed of round and flat cells, which were morphologically similar to ECs (Fig. 3A). These structures joined with each other and constituted a network of tubes with a smooth surface (Fig. 3B). Further observations using a TEM revealed the presence of lumens and gap junctions in the section of tubular structures (Fig. 3C). The lumens were surrounded by several round and flat cells, which were connected by tight junctions (Fig. 3D). These structures were similar to those of capillaries during early embryo development.
Examination of the endothelial-like cells in the EBs derived from human ESCs. Expression levels of vWF, an established endothelial marker (22), were analyzed on the EBs by immunofluorescence staining. On the tubular structures of the EBs stimulated by TGF- $\beta 1$, marked vWF staining was observed, while only a limited number of vWF positive cells were observed on the tubular structures from the control group (Fig. 4A and B). In addition, the EBs were harvested and total RNA was extracted for semiquantitative PCR analysis. The two markers of endothelial cells, CD31 and FLK1, exhibited higher expression levels in the EBs treated with TGF- $\beta 1$ compared with those from the control group (Fig. 4C), indicating that TGF- $\beta 1$ induced an increase in differentiated cells with endothelial cell characteristics.

\section{Discussion}

Previously, a human ESC line derived from ICM was established and characterized. In the current study, these ESCs were employed and the development of EBs stimulated by TGF- $\beta 1$ was investigated. Light and electron microscopic observations demonstrated that TGF- $\beta 1$ induced the in vitro differentiation 
A

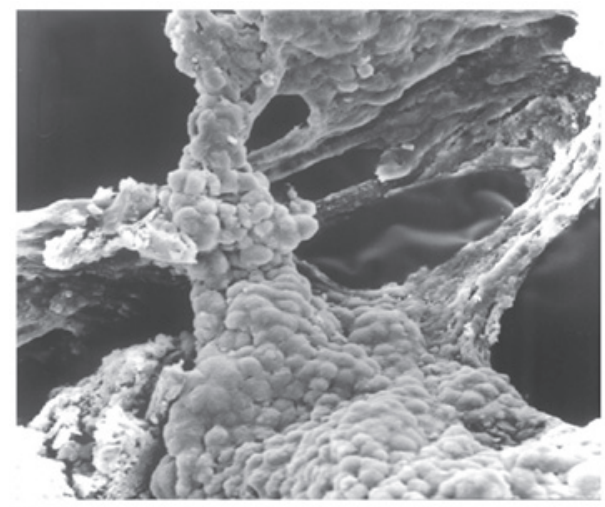

C

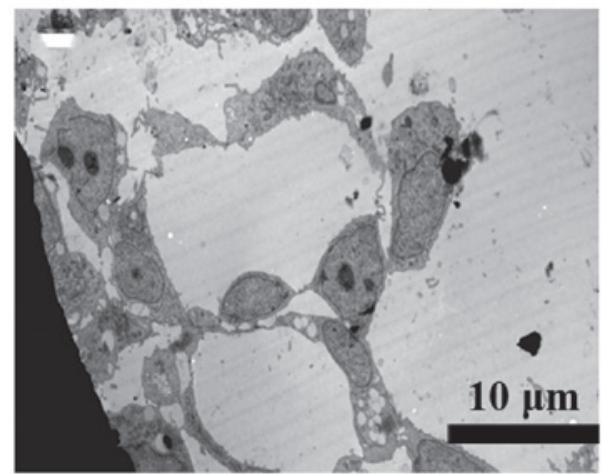

B

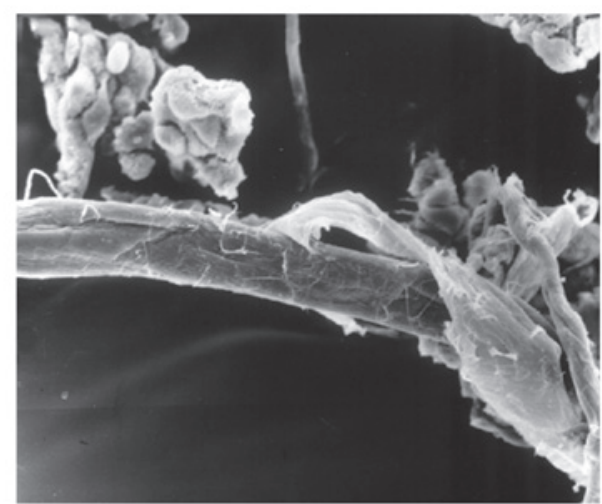

D

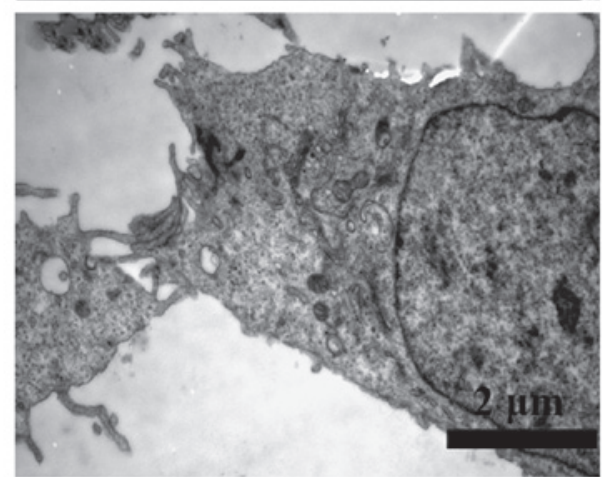

Figure 3. Vascular-like structures of EBs were observed with electron microscopy. SEM images revealed that (A) the tube wall was composed of round and flat cells, and (B) with the elongation of tube-like structures, the tube wall became smooth. TEM images revealed that (C) vascular-like structures had lumens surrounded by flat endothelial-like cells and (D) neighboring cells were connected by tight junctions. SEM, scanning electron microscope; TEM, transmission electron microscope; EBs, embryoid bodies.

A



B



C

\section{TGFß1}

Flk1

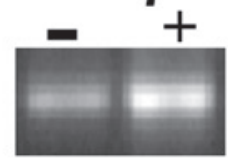

CD31



$\beta$-actin

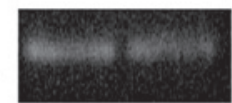

Figure 4. Expression of endothelial cell specific markers on EBs with vascular-like structures. Immunostaining of vWF on vascular-like structures of EBs in the (A) control and (B) TGF- $\beta 1$-treated groups. (C) Semiquantitative PCR revealed increased expression levels of FLK1 and CD31 in the EBs treated with TGF- $\beta 1$. TGF, transforming growth factor; EB, embryoid bodies; vWF, von Willebrand factor; PCR, polymerase chain reaction; FLK1, fetal liver kinase-1.

of embryonic stem cells into ECs, as well as the formation of vascular-like structures. The vascular identity of the cells in the EBs was validated by the expression of endothelial cell markers. In addition, TGF- $\beta 1$ promoted the differentiation of cardiomyocyte-like beating cells in EBs.

Human HSCs require coculture on mitotically inactivated MEFs, which cannot be substituted by the addition of leukemia inhibitory factor $(1,23)$. However, the addition of TGF- $\beta 1$ and other soluble factors, including bFGF and insulin-like growth factor, demonstrated a supportive role in the maintenance and propagation of human ESCs in culture $(12,14,24)$. In addition, TGF- $\beta 1$ has been shown to affect the cell fate decisions during epithelial-mesenchymal transition by upregulating surviving-associated proteins (25).
In this study, TGF- $\beta 1$ was shown to differentially regulate the differentiation of human ESCs and promote an endothelial cell fate. Although the mechanisms are not clear, upregulation of FLK1 expression may play an important role in this process. The FLK1 gene encodes vascular endothelial growth factor receptor 2 (VEGFR2), the major functional receptor of VEGF in ECs (26). Upon stimulation by TGF- $\beta 1$, SMAD3 becomes phosphorylated and forms a complex with SMAD4. These SMAD complexes translocate into the nucleus, where they bind to the promoter region of the FLK1 gene, thereby activating transcription (27). In the current study, EBs stimulated by TGF- $\beta 1$ exhibited marked mRNA expression of FLK1, supporting the role in mediating TGF- $\beta 1$-regulated cell fate decisions. 
TGF- $\beta 1$ and its isoforms regulate a variety of diverse biological functions, and the role of TGF- $\beta$ l in vascular development is complicated. TGF- $\beta 1$ stimulates in vivo angiogenesis (28-30), but directly inhibits the proliferation of ECs in vitro (31-34). TGF- $\beta 1$-stimulated induction of angiogenesis requires EC apoptosis, which occurs via autocrine/paracrine stimulation of VEGF expression and signaling via VEGFR2 (35). In vitro, TGF- $\beta 1$ induces tube formation when ECs are cultured inside three-dimensional collagen gels $(36,37)$. In the current study, TGF- $\beta 1$ was shown to promote vascular tube formation in EBs. Tube formation is a key process during vascular development, and vascular endothelial cadherin (VE-cadherin) is the cell adhesion molecule essential for this process $(38,39)$. VE-cadherin facilitates homotypic interactions between ECs and is strictly required for the polarization of ECs $(40,41)$. TGF- $\beta 1$ induces the rearrangement of the adherens junction complex by separating FLK1 from VE-cadherin and increasing the associations between $\beta$-catenin and FLK1 or VE-cadherin (42). Therefore, TGF- $\beta 1$ may promote cells with an endothelial identity to interact with each other and form tubular-like structures in EBs.

A previous study demonstrated that transfection of ESCs with the porcine TGF- $\beta 1$ gene permits vascular development from murine ESCs in culture (19). Under electron microscopy, the tubular structures observed in transfected murine EBs were similar to those from the human EBs stimulated by extracellular TGF- $\beta 1$ in the present study. All these structures were composed by the cells expressing EC markers. Therefore, extracellular TGF- $\beta 1$ and the transfected TGF- $\beta 1$ gene can induce vascular-like structures in EBs, possibly by activating downstream TGF- $\beta 1$ signaling in ESCs. The results indicated that TGF- $\beta 1$ is closely associated with the formation of vascular structure.

Cardiomyocyte-like cells derived from human ESCs have been actively pursued as a novel therapeutic to repair regions of damaged hearts. Studies on mouse embryonic development identified the TGF- $\beta$ superfamily member, activin $A$, and bone morphogenic protein 4, as key inducers of mesoderm and cardiovascular differentiation (43). In addition, TGF- $\beta 1$ induces the differentiation of human cardiac progenitor cells into beating cardiomyocytes with characteristic cross striations (44). In the present study, TGF- $\beta 1$ was shown to promote the differentiation of human ESCs to cardiomyocyte-like beating cells in EBs, consistent with the role of TGF- $\beta 1$ in supporting stem cell differentiation towards functional cardiomyocytes. Therefore, components of the TGF- $\beta$ signaling pathway may be used to manipulate human ESCs to regenerate myocardium for cell-based therapy.

In conclusion, the present study has demonstrated that extracellular TGF- $\beta 1$ promotes a cardiovascular fate of human ESCs in culture. The results indicate that TGF- $\beta 1$ can be used as a stimulator for the production of human ESC-derived ECs, cardiomyocytes and forming vascular tube structures. These observations may help to improve the methods of propagating specific cell types for the clinical therapy of cardiovascular diseases. Further studies are required to dissect the molecular mechanisms underlying the function of TGF- $\beta 1$ on cell fate decisions and vascular tube formation.

\section{Acknowledgements}

The study was supported by grants from the Natural Science Foundation of Shandong Province (no. ZR2009CQ001), the Science and Technology Development Plan of Shandong Province (no. 2011GSF11839) and the Medical Science and Technology Development Plan of Shandong Province (no. 2009-QW016). The authors are grateful for the support received from Shandong Taishan Scholarship (Ju Liu).

\section{References}

1. Thomson JA, Itskovitz-Eldor J, Shapiro SS, et al: Embryonic stem cell lines derived from human blastocysts. Science 282: 1145-1147, 1998.

2. Irion S, Nostro MC, Kattman SJ and Keller GM: Directed differentiation of pluripotent stem cells: from developmental biology to therapeutic applications. Cold Spring Harb Symp Quant Biol 73: $101-110,2008$.

3. Murry CE and Keller G: Differentiation of embryonic stem cells to clinically relevant populations: lessons from embryonic development. Cell 132: 661-680, 2008.

4. Murry CE, Reinecke H and Pabon LM: Regeneration gaps: observations on stem cells and cardiac repair. J Am Coll Cardiol 47: 1777-1785, 2006.

5. Freund $C$ and Mummery CL: Prospects for pluripotent stem cell-derived cardiomyocytes in cardiac cell therapy and as disease models. J Cell Biochem 107: 592-599, 2009.

6. Avery S, Zafarana G, Gokhale PJ and Andrews PW: The role of SMAD4 in human embryonic stem cell self-renewal and stem cell fate. Stem Cells 28: 863-873, 2010.

7. Poon E, Clermont F, Firpo MT and Akhurst RJ: TGFbeta inhibition of yolk-sac-like differentiation of human embryonic stem-cell-derived embryoid bodies illustrates differences between early mouse and human development. J Cell Sci 119: 759-768, 2006.

8. Massagué $J$ and Wotton D: Transcriptional control by the TGF-beta/Smad signaling system. EMBO J 19: 1745-1754, 2000.

9. Doetschman T, Shull M, Kier A and Coffin JD: Embryonic stem cell model systems for vascular morphogenesis and cardiac disorders. Hypertension 22: 618-629, 1993.

10. Shull MM, Ormsby I, Kier AB, et al: Targeted disruption of the mouse transforming growth factor-beta 1 gene results in multifocal inflammatory disease. Nature 359: 693-699, 1992.

11. Oshima M, Oshima $\mathrm{H}$ and Taketo MM: TGF-beta receptor type II deficiency results in defects of yolk sac hematopoiesis and vasculogenesis. Dev Biol 179: 297-302, 1996.

12. Vallier L, Alexander M and Pedersen RA: Activin/Nodal and FGF pathways cooperate to maintain pluripotency of human embryonic stem cells. J Cell Sci 118: 4495-4509, 2005.

13. Besser D: Expression of nodal, lefty-a, and lefty-B in undifferentiated human embryonic stem cells requires activation of Smad2/3. J Biol Chem 279: 45076-45084, 2004.

14. James D, Levine AJ, Besser D and Hemmati-Brivanlou A: TGFbeta/activin/nodal signaling is necessary for the maintenance of pluripotency in human embryonic stem cells. Development 132: 1273-1282, 2005.

15. Ng YS, Ramsauer M,Loureiro RMand D'Amore PA:Identification of genes involved in VEGF-mediated vascular morphogenesis using embryonic stem cell-derived cystic embryoid bodies. Lab Invest 84: 1209-1218, 2004.

16. Gendron RL, Tsai FY, Paradis H and Arceci RJ: Induction of embryonic vasculogenesis by bFGF and LIF in vitro and in vivo. Dev Biol 177: 332-346, 1996.

17. Hirashima M, Kataoka H, Nishikawa S, et al: Maturation of embryonic stem cells into endothelial cells in an in vitro model of vasculogenesis. Blood 93: 1253-1263, 1999.

18. Goumans MJ, Zwijsen A, van Rooijen MA, et al: Transforming growth factor-beta signalling in extraembryonic mesoderm is required for yolk sac vasculogenesis in mice. Development 126: 3473-3483, 1999.

19. Zhang XJ, Tsung HC, Caen JP, Li XL, Yao Z and Han ZC: Vasculogenesis from embryonic bodies of murine embryonic stem cells transfected by Tgf-beta1 gene. Endothelium 6: 95-106, 1998.

20. Zhang WJ and Cao YL: Stem cell, the basis for tissue and organ reconstruction. Zhongguo Yi Xue Ke Xue Yuan Xue Bao 27: 662-664, 2005 (In Chinese). 
21. Wu CF, Tsung HC, Zhang WJ, et al: Improved cryopreservation of human embryonic stem cells with trehalose. Reprod Biomed Online 11: 733-739, 2005.

22. Wall RT, Counts RB, Harker LA and Striker GE: Binding and release of factor VIII/von Willebrand's factor by human endothelial cells. Br J Haematol 46: 287-298, 1980.

23. Dahéron L, Opitz SL, Zaehres H, et al: LIF/STAT3 signaling fails to maintain self-renewal of human embryonic stem cells. Stem Cells 22: 770-778, 2004

24. Bendall SC, Stewart MH, Menendez P, et al: IGF and FGF cooperatively establish the regulatory stem cell niche of pluripotent human cells in vitro. Nature 448: 1015-1021, 2007.

25. Lee JS, Seo TW, Yi JH, et al: CHIP has a protective role against oxidative stress-induced cell death through specific regulation of endonuclease G. Cell Death Dis 4: e666, 2013.

26. Shibuya M: Tyrosine kinase receptor Flt/VEGFR family: Its characterization related to angiogenesis and cancer. Genes Cancer 1: 1119-1123, 2010.

27. Jeon SH, Chae BC, Kim HA, et al: Mechanisms underlying TGF-beta1-induced expression of VEGF and Flk-1 in mouse macrophages and their implications for angiogenesis. J Leukoc Biol 81: 557-566, 2007.

28. Leibovich SJ and Wiseman DM: Macrophages, wound repair and angiogenesis. Prog Clin Biol Res 266: 131-145, 1988.

29. Park C, Kim TM and Malik AB: Transcriptional regulation of endothelial cell and vascular development. Circ Res 112: 1380-1400, 2013

30. Roberts AB, Sporn MB, Assoian RK, et al: Transforming growth factor type beta: rapid induction of fibrosis and angiogenesis in vivo and stimulation of collagen formation in vitro. Proc Nat Acad Sci USA 83: 4167-4171, 1986.

31. Carmeliet P, Ferreira V, Breier G, et al: Abnormal blood vessel development and lethality in embryos lacking a single VEGF allele. Nature 380: 435-439, 1996.

32. Baird A and Durkin T: Inhibition of endothelial cell proliferation by type beta-transforming growth factor: interactions with acidic and basic fibroblast growth factors. Biochem Biophys Res Commun 138: 476-482, 1986.
33. Heimark RL, Twardzik DR and Schwartz SM: Inhibition of endothelial regeneration by type-beta transforming growth factor from platelets. Science 233: 1078-1080, 1986.

34. Maharaj AS, Saint-Geniez M, Maldonado AE and D'Amore PA: Vascular endothelial growth factor localization in the adult. Am J Pathol 168: 639-648, 2006.

35. Ferrara N and Bunting S: Vascular endothelial growth factor, a specific regulator of angiogenesis. Curr Opin Nephrol Hypertens 5: 35-44, 1996

36. Ingber DE, Madri JA and Jamieson JD: Role of basal lamina in neoplastic disorganization of tissue architecture. Proc Natl Acad Sci USA 78: 3901-3905, 1981.

37. Merwin JR, Anderson JM, Kocher O, Van Itallie CM and Madri JA: Transforming growth factor beta 1 modulates extracellular matrix organization and cell-cell junctional complex formation during in vitro angiogenesis. J Cell Physiol 142: $117-128,1990$.

38. Cavallaro U, Liebner S and Dejana E: Endothelial cadherins and tumor angiogenesis. Exp Cell Res 312: 659-667, 2006.

39. Lammert E and Axnick J: Vascular lumen formation. Cold Spring Harb Perspect Med 2: a006619, 2012.

40. Lampugnani MG, Orsenigo F, Rudini N, et al: CCM1 regulates vascular-lumen organization by inducing endothelial polarity. J Cell Sci 123: 1073-1080, 2010.

41. Strilić B, Kucera T, Eglinger J, et al: The molecular basis of vascular lumen formation in the developing mouse aorta. Dev Cell 17: 505-515, 2009.

42. Cook BD, Ferrari G, Pintucci G and Mignatti P: TGF-beta1 induces rearrangement of FLK-1-VE-cadherin-beta-catenin complex at the adherens junction through VEGF-mediated signaling. J Cell Biochem 105: 1367-1373, 2008.

43. Mignone JL, Kreutziger KL, Paige SL and Murry CE: Cardiogenesis from human embryonic stem cells. Circ J 74 2517-2526, 2010.

44. Goumans MJ, de Boer TP, Smits AM, et al: TGF-beta1 induces efficient differentiation of human cardiomyocyte progenitor cells into functional cardiomyocytes in vitro. Stem Cell Res 1: 138-149, 2007. 